\title{
The Culture of Employee Learning- Which Way for South Africa?
}

\author{
George Mavunga $^{1} \&$ Michael Cross ${ }^{2}$ \\ ${ }^{1}$ Academic Development Centre, University of Johannesburg, South Africa \\ ${ }^{2}$ Department of Education and Curriculum Studies, University of Johannesburg, South Africa \\ Correspondence: George Mavunga, Academic Development Centre, University of Johannesburg, South Africa. \\ E-mail: gmavunga@uj.ac.za
}

Received: August 22, 2015

Accepted: September 24, 2015

Online Published: October 20, 2015

doi:10.5430/ijhe.v4n4p223

URL: http://dx.doi.org/10.5430/ijhe.v4n4p223

\begin{abstract}
Employee learning which is known by terms such as human capital development and lifelong learning is an aspect of post-school learning which people engage in for purposes of enhancing their work-related competencies and possibly achieve upward professional mobility. There are different views on how best employee learning can be achieved at organizational and national levels, a debate which is currently alive in South Africa. The genesis of this debate is in the continued manifestation of aspects of the country's history such as socio-economic inequalities as well as how employee learning can be used to narrow them. This article looks at the concept of the culture of employee learning in terms of the theories on the basis of which its character is determined. Two such theories are Human Capital Theory and Critical Realism. Through application of these theories to the South African context of employee learning, the article concludes by offering suggestions on the direction which the country could take to create a sustainable culture of employee learning which might assist with addressing, amongst other problems, the challenge of socio-economic inequality which continues to haunt the country twenty one years after 1994 .
\end{abstract}

Keywords: Employee, Learning, Culture, Critical realism, Human Capital Theory

\section{Introduction}

While globalization has brought a considerable number of economic and social benefits, it is also associated with a number of challenges. One of these is the stiff competition for markets, not just amongst different companies, but different countries as well. These markets, whether consumer or business, are increasingly demanding quality products and services which can only be respectively produced and delivered by highly competent employees. This calls for what Christian (2015, p. 6) calls "..high-road strategies" which are both internal and external to organizations and enable them to become competitive. One of the internal high-road strategies is employee learning which, in turn, translates to a national imperative in light of the need for national economic competitiveness, (Christian, 2015; Maluleke 2014). Similarly, Durkovic (2009, p. 64) says, "Survival in the global economic system requires permanent update of knowledge, skills, abilities and the adoption of new knowledge." As a result, most countries in the developing world, including South Africa, are grappling with the question as to how they can engender a strong culture of employee learning in their citizens.

In order to cultivate a national culture of employee learning, most governments have put in place legislation, policies and programmes aimed at enabling their citizens to acquire high-level knowledge and competencies. In the case of South Africa, Marwala (2015) argues that if the country is to live up to its billing as a developmental state and empower her people intellectually, socially and economically, it is not enough to educate her citizens just to under-graduate level. Rather, efforts need to be ploughed towards educating people to post-graduate level as it is the only way in which the human capacity to achieve the country's developmental goals can be achieved. It needs to be noted, however, that implementation constraints notwithstanding, South Africa has made a lot of strides in terms of trying to ensure that its citizens continuously engage in post-school learning.

If a culture of continuous learning is to take route in any country, at organizational level, policies and programmes must also be put in place for its cultivation. Otherwise organizations will find themselves staffed with employees who have obsolete knowledge which is a worthless currency in the modern, fast-changing economy. As Conner \& Clawson (2004, p.326), say, "Today it seems that organizations need to be able to do more than just adapt; they must become agile in the face of constantly changing conditions." Intelligent response on the part of organizations entails making learning a pivotal part of their strategies. In order to make this possible, leaders in organizations must ask 
themselves how they can dramatically increase their employees' capacity to learn. Individual employees themselves will also need to embrace the organizational and national culture of employee learning or they will find themselves spectators of both formal and informal economic activities. In South Africa, this can only worsen the already unacceptably high levels of socio-economic inequity.

Despite all the efforts aimed at ensuring post-school learning, especially amongst those in formal employment, the shortage of skills in South Africa is said to be so serious that it is considered industry's toughest challenge (Workplace Staff, 2014). This has negative implications both socially and economically. For example, according to the UNDP (2014, p.2), “... when compared with other developing countries, South Africa usually ranks among the last countries in the people category" (Swanepoel et al 2001 p.493). Woolard \& Woolard in Kraak \& Press (2008, p.69) also say, "Despite ranking as one of the fifty wealthiest nations on the basis of per capita GDP, South Africa ranked $115^{\text {th }}$ of 175 countries in terms of its Human Development Index in 2003" (UNDP, 2004). For 2014-2015, the country actually slipped from position 53 to 56 (UNDP, 2015). Twenty one years after 1994, the country therefore still finds itself at a crossroads of economic and social development characterized by huge inequalities. The task of developing and implementing policies and programs which facilitate job creation, narrow income differentials and redress inequalities in access to wealth is still so huge that South Africa, like Brazil, has a very high gini coefficient, meaning that it has one of the widest gaps between the rich and the poor. For example, according to Lehola (2014), for the year 2011, the richest $20 \%$ of the country's population accounted for over $61 \%$ of the country's consumption while the bottom $20 \%$ accounted for only $4.5 \%$. In addition, the country's Human Development Index in respect of years spent in learning institutions by people aged twenty five and above for the year 2013 is very low (UNDP, 2014).

The continuing challenge of socio-economic inequality in South Africa which emanates from the skills shortage, especially amongst the majority of its black population does not augur well for the country's economic, social and political future. For example, Msomi (2014, p.4) quotes Trevor Manuel, the former Minister of National Planning as expressing the fear that the shortage of skills in South Africa, which itself is a result of a poor education system, “... could make it difficult to grow the South African economy." This would contribute not only to a stalling of the country's economic progress, but also possibly a reversal of its gains and unravelling of the foundational aspects of its democracy and the gains of the social and economic stability that the government has been trying to consolidate since 1994. There is, therefore, concentrated focus on the supply-side approach with emphasis on measures such as education and training, with the ultimate aim of enabling every citizen to not just actively participate in the economy, but also share in its fruits. Yet under- and un-employment continue to be a big social problem in the country. The question therefore arises as to the approach which the country should take to engender a culture of employee learning which will effectively address the shortage of skills and, in the process, narrow the socio-economic inequalities which it continues to face.

The problem of under- and un-employment in South Africa, as explained above is said to have its roots in the apartheid policies as a result of which, according to Baatjes in Kraak \& Press (2008, p. 206), “...millions of black South Africans reached adulthood without being able to read in any one language, and the black workforce was largely uneducated and unskilled." Currently, the problem is said to be attributable to two other factors, namely, South African companies' philanthropic approach to skills development and failure by the country to get the basics right in terms of early childhood and primary school education. As a result of the later, for example, a large number of children in the country can neither read nor count even when they have books. In the long term, this translates to a shortage of high level knowledge and competencies needed for economic development (CSIR ICC, 2015). Out of the realization of the long-term effects of this scenario, the South African government had to adopt measures to address the problem of skills shortage and its twin challenges of un- and under-employment. One of these measures was the Accelerated Shared Growth Initiative (ASGISA) which aimed at reducing the country's unemployment rate from 30\% to $15 \%$ by 2014 (George, Surgey \& Gow, 2014). The government's approach to the problem has, however, been blamed for its failure to formulate policies and strategies which systematically and effectively address the problem and, in some cases, policy contradictions. Under such circumstances, therefore, attempts by South African organizations to inculcate a strong culture of work-related and lifelong learning in their employees bear little or no fruit.

In most South African organizations there are a number of staff development programmes targeted at middle and senior management. Yet, for low-level staff such as office administrators and unskilled manual workers, there are very limited opportunities for engaging in work-related learning programmes that would facilitate upward mobility career-wise. (Tshilongamulenzhe \& Coetzee, p.2013). Yet most such organizations have very grand vision and mission statements which envisage a very successful future. This therefore raises the question as to how these 
organizations hope to realize such a future without paying much attention to the learning needs of their low-level employees some of whom are at the critical interface of the organizations and external stakeholders such as customers, suppliers and distributors. This lack of attention to the work-related learning needs of support staff can manifest itself at two levels, at least; 1) poor service delivery by some low-level employees and 2) the low-level employees' frustration over lack of opportunities to improve themselves.

This paper aims to provide suggestions on the direction which South Africa should take in order to create a culture of employee learning that will help to address the problems the country currently faces such as socio-economic inequality, unemployment and unemployability. The article does this by explaining the concept of the culture employee learning and its determinants such as Human Capital Theory and Critical Realism. It also outlines three employee learning models and discusses how these may be applicable to the South African employee learning context. Finally, the paper suggests a possible South African employee learning map for the future.

\section{The culture of employee learning: towards a definition}

Employee learning as a field of study has historically developed from being known as adult education, recurrent education, continuing education, human resource development, community education, lifelong education to the present day when it is referred to as lifelong learning (Jarvis, 2007). While there have been a lot of studies in the field in general, there is a dearth of research on the culture of such learning. Most of the work on employee learning has tended to focus on the rationale for it as well as the attendant pedagogy. Yet, in our view, a cogent characterization of the culture of employee learning would help greatly with identification of measures that need to be taken to enhance it, especially in the context of the South African society where the legacy of the country's past still continues to strongly manifest itself to the detriment of efforts to bring about socio-economic equality amongst its citizens.

Jarvis (2007) contends that culture is too complex a phenomenon to define as it is not conceptualized in the same way by different people. He, however, says for purposes of simplifying issues, it can be defined as "...the sum total of knowledge, values, beliefs, attitudes of the society." (Jarvis, 2007, p.316). Similarly, Schein $(2004$, p.128) defines culture as "...the pattern of learned assumptions that has worked well enough to be considered valid and, therefore, to be taught to new members as the correct way to perceive, think and feel in relation to the problems of survival and integration. An implication from Schein's (2004) definition of culture is that it has both overt and covert aspects. To fully understand the character of any culture one, therefore, needs to analyze both its overt and covert features (Schein, 2004). The later are usually less conspicuous but, like the easily observable, they are often characterized by certain decipherable patterns of behavior.

Just like we can talk about the culture of a particular society, nation or generation, we can talk about the culture of a specific organization. This is generally referred to as organizational culture which Schein in Conner \& Clawson, (2004, p.128) defines as, "...the pattern of learned assumptions that has worked well enough to be considered valid and, therefore, to be taught to new members as the correct way to perceive, think, and feel in relation to the problems of survival and integration." Organizational culture is, therefore, the sum total of shared values that enable members of an organizational community understand how things work in the organization. It therefore helps in guiding organizational members' thinking and behavior as well as influencing organizational processes. Mullins (2005, p.721) says, put simply, organizational culture refers to, '... how things are done here.' Examples of aspects of organizational culture could be the nature of intra and inter-group relationships; the nature relationships with external stakeholders; safety practices amongst many other facets of life in the organization. To this list can be added the culture of employee learning which usually is a derivative of the broad organizational culture. This sub-culture manifests itself in the learning activities that both individuals and groups engage in according to Senge (2006) and Jones (1996). It, however, needs to be noted that, in keeping with Schein's (2004) characterization of culture as being layered referred to earlier, the culture of employee learning can also have very overt features beneath which can be found the not so obvious. A description of the culture of employee learning in any organization is therefore incomplete without reference to both its overt and covert characteristics.

\section{Determinants of the culture of employee learning}

There are two broad views on the determinants of the culture of employee learning. The first of these is the Human Capital Theory (HCT) on the basis of which the culture of employee learning is seen as emerging from the policies, strategies and programmes put in place by the employer to encourage employee learning. The second view is based on Critical Realism (CR) which advocates a deeper sociological analysis of the context in which employee learning takes place for the holistic characterization of its culture. 


\subsection{Human Capital Theory (HCT)}

Human Capital Theory emerged in the USA after the Second World War. The theory looks at human beings as a factor of production in any business just like land and capital goods. Livingstone (1997, p.1) says, the belief in HCT is that, "...when the resource is effectively exploited, the results are profitable both for the enterprise and society as a whole" while Almenndarez (2011, p.1), says the theory "...rests on the assumption that formal education is highly instrumental and necessary to improve the productive capacity of a population." Gillies (2014. p.79) also says HCT conceptualizes education as "...a form of capital investment which repays individuals in improved employment opportunities and financial rewards and nation states in greater economic activities and growth." In other words, the basic argument in HCT is that education increases productivity and efficiency of employees by increasing the level of cognitive stock of economically productive human capability (Almenndarez, 2011). Such capability is born of innate abilities and investment in human beings both of which are seen as being equally, or even more worthwhile, than investment in physical capital. This is perhaps why Livingstone (1997, p.1), concludes that according to HCT, when people's learning capacities are, “... effectively exploited, the results are profitable both for the enterprise and for society as a whole."

\subsubsection{Implications of Human Capital Theory for the culture of employee learning}

According to Olaniyan and Okemakinde (2008), HCT has several implications for employee learning and development. The first of these is that where the intention by the state or any organization is to improve the performance and efficiency of workers, it has to be accompanied by a concomitant investment in their learning activities. This implies that employee learning becomes largely dependent on the policies and programmes initiated by the state or the organization. Naturally, therefore, the values and attitudes espoused by the state or employer with respect to employee learning, where they are the principal funders of such learning are strongly reflected in the resultant culture of this learning. For example, if the state or employer places emphasis on demonstration of competencies after an employee has gone through a particular learning programme, the learning programmes will usually be oriented towards assessments. This perhaps explains the emphasis that is evident in the outcomes-based education (OBE) driven National Qualifications Framework which, until recently was the guiding philosophy for both basic and post-school education in South Africa. Conflict and tension can, however, inadvertently emerge as aspects of the culture of employee learning, especially in situations where employees want to pursue their own learning independently of the employer's expectations.

A second implication for the culture of employee learning arising from HCT from the need for employee learning that suits the state or employer's expectations, according to Olaniyan and Okemakinde (2008). They argue that in a situation where there is competition for resources, which are inherently finite, sometimes investment in employee learning is among the first areas where budgetary cuts are implemented. This has the potential to limit training and skills development opportunities for the employees thus resulting in very little or no employee learning taking place. Organizations in which this happens are therefore likely to end up with a culture of employee learning which at best is lethargic and despondent and, barely existent in any significantly identifiable way, at worst.

The third implication for the culture of employee learning arising from HCT stems from the natural expectation that the higher the investment in a learning programmes, the higher should be the earnings of the individuals engaged in the program upon successful completion (Olaniyan and Okemakinde, 2008) Yet, this does not always follow as some forms of learning requiring heavy investment do not always guarantee high earnings, especially in the context of the economic crises such as the economic depression which a number of countries in the world recently went through (Salim and Vally, 2014). In situations where employees intending to engage in particular forms of formal learning see their colleagues who have gone through those programmes not earning as much as they would have expected or, in the worst of cases, even failing to secure employment commensurate with the levels of their educational attainment, this also has the potential to negatively impact on the culture of employee leaning.

\subsubsection{Limitations of Human Capital Theory}

The post-1945 expansionary era and the simultaneous increase of school participation rates and earned incomes in advanced industrial market economies gave credence to the view that more schooling would inevitably lead to economic success. (Livingstone 1997). The applicability of these claims has, however, been thrown into disarray since the 1970's, “... as school enrolments have continued to increase while average incomes have stagnated, unemployment rates have worsened and underemployment of highly schooled people has been recognized as a social problem." (Livingstone 1997, p.4). In addition, the validity of the claims in HCT has been questioned especially in light of the realization that they are "...antithetical to the values of sustainability and perpetuate the notions of exploitation and exhaustive profitability" (Gillies 2014, p.87). Furthermore, especially in the South African context, 
they ignore social, gender and racial disadvantage and inequality which themselves have a large bearing on educational attainment.

Another criticism levelled against HCT is that it makes the assumption that human beings, as rational egoists, will pursue educational qualifications in a bid to increase their earning capacity (Salim and Vally, 2014). Improved educational levels are therefore associated with improved productivity and earnings according to the theory. Critics of the theory, however, point to the uniqueness of situations which produce certain competencies and not others despite the demand for those other competencies. Moreover, the existence of high numbers of unemployed graduates in many countries of the world today is evidence that, in some cases, there is no direct relationship between level of education or skills and ease of finding employment or earning capacity. As Sibiya (2014) and Baatjies in Matshali (2014) argue, there is no linear relationship between education and employment. In other words, a formal qualification does not always guarantee one a job and increasingly, people are getting into jobs which they did not specialize in at tertiary education level. It therefore needs to be noted that the role of education is not limited to just churning out compliant robotic workers. The need for full participation in an economy also requires that institutions of learning produce individuals who are more than just workers but also responsible citizens who have enough social intelligence to show concern for fellow human beings and the environment. In addition, it also needs to be accepted that unemployment, especially in a country like South Africa in which the remnants of racial segregation still manifest themselves, can be a result of factors that have nothing to do with people's levels of education but underlying structural inequalities in the economy (Vally \& Motala, 2014).

In the case of South African universities, pursuit of the neo-liberal agenda has seen the introduction of performativity regimes, as a result of which universities are becoming more and more corporate in outlook. 'Non-core business' such as the work-related learning for low-level employees such as administrative assistants which is an imperative, is therefore getting pushed further and further to the periphery. Likely to arise from such a scenario is a depreciation in the value that employees place on their own work-related learning.

Proponents of HCT have also been criticized for overlooking the possibility of a mismatch between the skills demanded by employers and those which the employees actually use in doing their work. For example, Batjes (2014) reports on a textile factory study which showed incongruence between the skills which the employer expected the employee to have at the point of recruitment and the competencies the employees needed in performing their tasks after being hired. She therefore slams the current discourse on employee learning, the skills shortage, unemployment and unemployability in South African for paying too much attention to credentialsim at the expense of a more critical analysis of the structural and historical social context in which these problems are manifesting themselves.

On the basis of the foregoing and similar arguments, there have been attempts to retool HCT. This has resulted in a downplaying of schooling and a shift of focus to, among other areas, lifelong job-related learning which sees the dynamic centre of human capital creation in the so-called 'learning organizations.' Senge (2006) proposes that such organizations can create intellectual capital by facilitating collaborative problem solving within their workforces. This, however, still fails to repair HCT because of the continuing gap between people's learning efforts and the declining numbers of commensurate jobs. For example, according to Livingstone (1997, p.4), “...more extensive surveys of work-related learning threaten to undermine learning organization revisions of HCT entirely, by exposing the lack of sustained relations between continued learning and earning for most workers." This implies a possible negative impact on the culture of employee learning built around HCT despite all the efforts which the so-called learning organizations may invest in the learning of their employees.

From the arguments raised above, it can be concluded that the culture of employee learning in any organization cannot be analyzed only in terms of HCT or revisions of it such as the concept of learning organizations. This is because these theories are too linear as they look at the causal relationship between state or organizational investment in learning and the resultant culture of employee learning as unidirectional. In addition, the theory, in focusing mainly on organization systems and design, largely ignores what individuals on their own want to learn and how they learn (Scarborough, Swan and Preston in Armstrong 2007). Moreover, some scholars find the idea of organizations investing in their employees through human resources development initiatives, in order for the employers to realize greater returns, objectionable and abhorrent Jarvis (2007). In addition, looking at organizations as learning systems is also a limited notion as organizations are products of visions, ideas, norms and beliefs. The sum total of their architecture is therefore more malleable than that of their material structure. As learning agents of their organizations, human beings behave in ways that cannot be easily systematized. The culture and environment therefore become more critical as determinants of how employee learning takes place than the organizational systems (Hoyle in Armstrong, 2007). Taking culture and environment into consideration enables one to avoid a single, best-practice 
framework for employee learning which in turn leads to prescriptive systematic training which, however, has over the years neither delivered full potential nor lived up to the aspirations of all employees (Easterby-Smith in Armstrong, 2007). In looking at employee learning the focus should thus be on creating a climate conducive to collaborative and self-managed learning. This necessitates the use of a more critical theory to analyse the culture of employee learning, hence our choice of critical realism.

\section{Critical realism $(C R)$}

As pointed out above, there are limitations in looking at the culture of employee learning using the concept of the learning organization as suggested by Senge (2006) and other HCT proponents. One useful theory to use is critical realism (CR) as propounded by philosophers such as Bhaskar (1998) and Archer (2006). Critical realism theory according to http:www.fsc.yorku.ca prioritizes ontology, that is, the study of being or existence over epistemology, that is, study of the way knowledge is obtained. Critical realists therefore warn against committing the sin of 'epistemic fallacy' which, according to Archer in Mutch (2004) is confusing knowledge of what exists with that which actually exists. This is because, for critical realists, the way the world is should guide the way knowledge is obtained. In other words, there is a reality which exists independent of its human conception. Critical realists posit that natural and social reality should be understood as an open stratified system of objects with causal powers (Morton, 2006). They also assert that the only way to understand the social world is through identification of the structures which generate the events and discourses that form social reality. This implies that there are unobservable events which cause the observable ones. For example, the social world can be understood if we understand the structures which generate unobservable events. This is important because it allows an investigator to distinguish between the event and what causes it.

When applied to a social phenomenon such as the culture of employee learning, CR helps us to appreciate that culture and society are generated by human activities. The role of the critical realist is to identify the real underlying structures and the mechanisms that combine to produce actual social events. The relationship between the two is, however, a mutually influential one because while humans shape society, they are in turn shaped by it. CR therefore calls for a deeper investigation of any social situation, going beyond the observable and investigating the mechanisms behind any event. It can thus be used to explain complex social events and rules out any superficial explanations. In terms of the culture of employee of learning this helps the researcher to raise questions pertaining to the bi-directional and sometimes, multi-directional causal relationships of the phenomena which he or she will be studying. It is for this reason that Jarvis (2007) categorizes some learners as pro-active, that is, those who take the initiative to learn on their own and others as reactive, that is those who respond to organizational learning initiatives. The culture of employee learning in any organization can be a function of both the employer-initiated programmers and the employees' own initiatives which can actually also contribute to the architecture if that culture.

With regard to employee learning, structure includes the government, the management of an organization and the different departments within the organization. Government as a structure therefore influences the culture of employee learning in that it comes up with legislation and policies governing employee learning. These influence the culture of employee learning in the sense that whatever activities the individual employee engages in, have to conform to the national employee learning legislation and policies. Sub-structures in an organization such as departments and worker representative organizations also influence the culture of employee learning in that they may have their own policies, rules and regulations governing the learning activities that employees may engage in as well as how and when this can be done. However, at organizational level there may also be informal structures such as study groups or teams which also have an influence on the individual employee's culture of employee learning.

Agency, according to Archer (2006) refers to the mandate which different structures in society have to influence the activities and therefore, by extension, the culture of that society. With regard to employee learning, agency refers, for example, to the extent of the power which structures such as the management in an organization has to force employees to engage in certain learning activities. Agents are generally collective in character, whether as a consequence of involuntary positioning, as a result of demographic factors such as age and gender, or corporate, where those with a perceived common interest act collectively (Archer in Mutch 2004). They are vehicles for the implementation of policies, rules and regulations and often they adjudicate on the extent to which different role players in society in general or in an organization, conform to the policies, rules and regulations. Berger in Jarvis (2007:194) concurs with this view when he says through agency, institutions "...provide procedures through which human conduct is patterned, compelled to go in grooves deemed desirable by society." In terms of employee learning, agency manifests itself in the way in which different structures exercise the power vested in them to determine the direction in which employees engage in work-related learning. While most structures derive their agency from 
formal systems such as legislation and policies, others derive it from informal systems such as learning teams that are formed from commonalities in learning goals being pursued by groups of employees. Regarding employee learning, agents also serve to select the curriculum, the facilitator as well as the time and venue of the learning activities. In some cases they also have a say over assessments and the criteria for success or failure and the rewards or punishment thereof. While all these roles of agency are true with respect to employee learning, Jarvis (2007) cautions that there is an extent to which such learning is so self-directed that we may not be able to decipher the role of external agency in it. There is therefore an extent to which the form of the culture of employee learning is a function of individual and not corporate agency. This is perhaps why Merton in Jarvis (2007) advises against agents pursuing organizational goals and seeking to maintain the organizational status quo through employee learning at the expense of the aspirations and sometimes, even capabilities, of the individual employees- the phenomenon of displaced goals.

An important implication to emerge from the foregoing is that the constituent components of structure do not always work harmoniously to shape the culture of employee learning. The agents that make up these structures may sometimes pull in opposite directions. The architecture of the culture of employee learning is therefore a function of how the employees at both individual and group level negotiate the often opposing interests of the agents that make up the different structures within the organization and, sometimes, even the broad society in which they exercise their desire to learn. One can conclude from the foregoing that, in addition to looking at the conspicuous aspects of the culture of employee learning such as the influence of the policies, strategies and infrastructure put in place by the employer on the nature of that culture, one needs to look at its often hidden dimensions such as its architecture resulting from employees' biographies; the informal forms of learning which employees may be engaged in; power dynamics involving different role players and the employees' mediation of the work-related learning programmes put in place by the employer.

\section{Employee learning models}

The culture of employee learning is not established in a vacuum. Rather, it takes place within the specific contexts of the national culture of employee learning. There are differences in the culture of employee learning amongst different countries arising mainly from differences in historical and economic contexts. An analysis of these models gives insight into the goals for, and beliefs about, employee learning which those who employ them have in mind. Out of each these models consequently arise different cultures of employee learning. There are several such models but in this paper only three and their applicability to the South African context are discussed. These are the market or Anglo-Saxon model, the social partnership or Asian Tigers model and the Germanic model.

\subsection{The market or Anglo-Saxon approach}

Based on HCT, the major assumption in this approach is that since individuals benefit from acquisition of general knowledge just like the companies benefit from the acquisition by employees of company-specific knowledge, the arrangements for either should be organised separately (Tshilongamulenzhe \& Coetzee, 2013). The implication here is that while individuals should be responsible for acquisition of general knowledge, organizations should provide programs for their employees to acquire work-specific knowledge. The culture of employee learning in an organization which adopts the market approach is therefore mainly characterized by linearity and conformity in the relationship between the learning programs initiated by the employer and the work-related learning activities which employees engage in. In such organizations we see learning programs with lists of learning activities which employees must engage in at the request of the employer. In some cases these programs are aligned to the vision and mission statements or strategic thrusts of the organization. The underlying assumption is that the employees lack the competences that will enable the organization to achieve its strategic goals. Management therefore takes a deficit approach aimed at bringing the employees' competencies up to a level which it is assumed will enable the organization to realize its strategic goals. This is widely reflected in the current discourse on employee learning in South Africa where the emphasis is on skills shortage, its effects and what needs to be done to solve it. Yet this emphasis on technical competence is beginning to be questioned as in reality most jobs actually require more than just technical competence for successful execution (Ngcwangu \& Balwanz, 2014) The covert aspects of employee learning such as attitudes and emotional intelligence therefore also need to be looked at as necessary facets to include in the employee learning discourse thus further widening the question as to how much is being done in the country to cultivate a strong culture of employee learning as opposed to the suggestions in the market approach because of its HCT roots.

One of the major arguments advanced in favor of the market approach is that it gives the employers a measure of autonomy in terms of the range of working practices and the way in which they are introduced into the workplace. Thus practices such as teamwork, performance management and training are left to management to make decisions 
on. Though it may appear that in this model, employee learning activities are the sole responsibility of employers, other stakeholders such as trade unions still have an influence especially on the extent to which managerial discretion can be exercised. Acquisition of work-relevant knowledge remains largely voluntary. In this model, therefore, there is very little scope for government intervention in employee learning. The only time when government intervenes is when there are market failures such as unemployment. Such intervention will be intended to encourage both employers and employees to engage in activities which enhance skills acquisition by employees. When this approach is used at national level, therefore, it may be difficult to characterize the national culture of employee learning as individual organizations will initiate employee learning activities in ways that best suit their interests.

The second disadvantage associated with the market approach is that there is no encouragement for the development of soft skills, for example, planning, inter-personal and communication skills as explained earlier. This is because employees, sometimes at the behest of the employer, focus only on skills that are directly specific to their jobs. If pressure is brought to bear on companies to maximize immediate returns, they may sacrifice learning activities for short term financial gains ((Tshilongamulenje \& Coetzee, 2013). Unfortunately, however, this may create a culture of employee learning in which employee-learning is sacrificed for profit, leading to a possible shortage of skills in the future.

Another disadvantage of the Anglo-Saxon approach is that in the countries in which it is followed there is no comprehensive national employee learning strategy. Firms tend to be guided only by short-term pressure. They are thus likely to be guided by short-term pressure. As such they are often prepared to pay high wages to those employees with the skills which are in high demand instead of investing in long-term employee learning programs. A possible consequence of this is the emergence of the so-called 'free-riding' employers who poach employees who will have been developed by others, further worsening the skills shortage crisis.

The market approach model inherently leads to a fragmented approach to the provision of employee learning programs. Under such circumstances, the national culture of employee learning is also fragmented in nature. There will be no coherence in terms of formulation of strategies and programs aimed at creating a national culture of employee learning. Individual entities tend to act independently in such an environment. This, in turn, results in persistent underinvestment in employee learning and poorly understood skills shortages. The only growth in skills that is experienced under such circumstances is that of lower-skilled, lower-paid employees who have no clear paths or development opportunities (Hall \& Lansbury) in Tshilongamulenzhe \& Coetzee (2013). Its disadvantages notwithstanding, the model has proven to be relatively successful in countries such as the UK, Australia and the USA. At national, sector and organizational level, South Africa borrows heavily from this approach as evidenced by the structure of employee learning programmes at all these levels and the upskilling discourse which characterizes these programmes.

\subsection{The social partnership approach or Asian Tigers model}

Characterized by a very high degree of government involvement in attempts to match the supply of, and demand for, skills in the labor market, this model is said to be the converse of the Anglo-Saxon model (DTI in Tshilongamulenzhe \& Coetzee, 2013). It is therefore a model relevant for countries that need to industrialize in a shorter period of time. This is because it supplements the operation of the market. The movement of the Asian Tigers from low- to high-skill economies is attributable to this model.

The social partnership approach is in essence a partnership-driven approach. Where it is adopted, strong cooperation amongst the social partners such as employers, trade unions and government at company, industry and national levels becomes an imperative. Since the model is premised on the need to develop a strong skills base across all sectors of the economy, emphasis will be placed on activities such as shared training schemes and pooled resources between companies which are then subsidized by government employee learning schemes. One of government's major roles in this model is formulation of policies that drive employee learning. For example, incentives training grants and reduced tax are given to companies which are willing to invest in employee learning. From this model is likely to arise a very regimented culture of employee learning in which nearly all aspects of employee learning are strongly determined by the key role players in the partnership. Examples of countries in which this model has been successfully implemented include Singapore, Taiwan and Korea. Inevitably driven by the need to correct past socio-economic injustices, South Africa reflects many elements of this model as seen, for example, in government involvement in employee learning through the enactment of related legislation and establishment of statutory bodies. However, because of systemic weaknesses, implementation has been a major weakness in the country.

Despite the successes emanating from it, the social partnership approach is faulted for its inherently high costs, administrative challenges and insensitivity to the needs of individual enterprises. In addition, employees are likely to 
have very little leeway to choose to engage in forms of work-related learning which are not in conformity with what is prescribed for them. The culture of employee learning arising from strict implementation of this model is likely to be characterized by resentment for, and resistance to, work-related learning. The model, is, however, still credited for the possibilities that it creates for employees to move across industries and to relocate during times of economic recession (Tshilongamulenzhe \& Coetzee, 2013). Secondly, all the social partners have incentives to leverage the joint regulatory bodies in order to broaden the scope of the provision of employee learning activities. This can assist to rectify market failures with respect to those learning activities initiated by the employer. The model therefore creates an employee learning culture characterized by greater likelihood of commitment to employee learning activities especially on the part of employers some of whom often attempt to evade this responsibility when it suits them. The problem, in most countries, however, seems to be the weakening of the cooperation amongst the social partners, namely government, trade unions and business. Once this happens, the resultant culture of employee learning is also most likely to be equally weak.

\subsection{The Germanic model}

The Germanic model is a hybrid of the market and social partnership models (Tshilongamulenzhe \& Coetzee, 2013). In this model employee learning programs and activities are to an extent driven by the market. There is, however, an extensive legal framework guiding the provision of learning to employees. This is done to limit the extent to which this can be left to the discretion of corporate managers. Stakeholders such as work councils also have a say in issues that have a bearing on employee learning.

The Germanic model is characterized by two important facets. The first of these is the need to ensure that all the social partners are part of the decision-making. This leaves managers with reduced freedom to maximize short term gains at the expense of the employees. In countries such as Germany and South Korea where the model has been adopted, through placing limitations on the actions of managers, the legislative framework put in place has helped to ensure the development of trust between employees and managers. The trust develops as a result of the obligation on the part of managers to have equal concern for the welfare of employees as for the return to shareholders. One disadvantage, though, is the lack of flexibility in the arrangement as the state, employers and the unions should reach consensus on all crucial employee learning-related issues (Tshilongamulenzhe \& Coetzee, 2013). South Africa also borrows from the Germanic model as shown not only by the legislative regime put in place to regulate employee learning but also the obligations for conformity which this legislation puts on organizations such as the annual submission of workplace skills plans and the need for representation of key stakeholders on training committees.

The other salient characteristic of the Germanic model is related to the German apprenticeship model in which employers and unions are bound together to enforce the apprenticeship system. This helps to create a culture of employee learning in which there is acquisition of high levels of relevant skills by employees. Countries such as South Africa and Singapore are said to have implemented some elements of this model.

Given that each of the models has both strengths and weaknesses, each country, taking into account its individual circumstances, will need to adapt different elements of each of the models to craft its long-term employee learning strategies. In the case of South Africa, because of its unique history, there is no single model of employee learning which can be prescribed for the country. What is needed is a multi-pronged approach to create a culture of employee learning which help employees to satisfy their work-related needs in both the short and long-term. (Tshilongamulenzhe \& Coetzee, 2013).

\section{The South African employee learning context}

Since 1994, the South African government has put in place an employee learning system which is a combination of various pieces of legislation and skills development strategies which it has respectively promulgated and crafted since 1994 in order to address the problems arising from the legacy of the country's past. The system is also meant to address current demands such as the need for the country to be economically competitive and give greater impetus to the socio-economic equity trajectory.

The government has set up a number of structures mandated with ensuring employee learning. All this was a result of combined efforts by government, labour, business, education and other stakeholders initially developing independent visions and then coming together to work towards what was supposed to be a common vision (Tshilongamulenzhe \& Coetzee, 2013). Examples of legislation meant to address problems in post-school education for both the employed and unemployed, include the Skills Development Act 97 of 1998; the Skills Development Levies Act 9 of 1999; the Skills Development Amendment Act 31 of 2003; the Skills Development Act 37 of 2008; the Skills Development Bill of 2011; the National Qualifications Framework (NQF) Act 67 of 2008; the South Africa 
Qualifications Authority Act 53 of 1995 and the Employment Equity Act (1998). In addition to these acts, the government has come up with blueprints such as the National Skills Development Strategy (NSDS) 1, 11 and 111. The latest document, launched by government to address the challenges in post-school education in the country is the White Paper for Post-School Education and Training which according to Nzimande (2013, p. viii) is meant to be, “... a vehicle with which to drive and deepen transformation of the entire post-schooling sector."

Forms of employee learning in South Africa include, learnerships, Adult Basic Education and Training (ABET), as well as certificate, diploma and degree programs. Skills development legislation in South Africa also provides for the establishment of Sector Education and Training Authorities (SETA's) whose major mandate, according to Edutel Skills Development (2010, p.84), is to oversee, “...the education and training needs of employers and employees who use similar materials, processes and technologies, make similar products or render similar services."

The pieces of legislation and strategies which the South African government has put in place post-1994 are deliberate attempts to ameliorate the effects of the legacy of apartheid in terms of socio-economic justice in the workplace.

Despite all the South African government's efforts to address the multi-faceted employee learning problems, the question, still remains as to whether these efforts will create a culture of employee learning in which there is appreciation at all levels of the need for employees to engage in work-related activities which not only benefit them but employers and the nation at large as well. For Nkosi (2014), there is very little hope that this is achievable as he observes that the crisis of skills shortage, unemployability and an ineffective national culture of employee learning continues to worsen as the SETA's continue to waste billions with very little to show for that expenditure. The Sunday Times (2012, p.5) in a commentary also cynically says, 'No amount of corrective legislation can empower those who have been kept illiterate and innumerate by a failing system to better their lives.'

\section{A possible way forward for South Africa}

As highlighted above, South Africa is still battling with finding its footing in terms of employee learning. One question which arises pertains to the approach which the country should take in order to effectively meet the work-related learning needs of the majority of its workers in order to achieve socio-economic equity as well as global competitiveness. The answer to this seems to lie in the nature of the culture of employee learning arising from the model which the country has tried to implement post-1994 at nationally and at organizational levels. Due to differences in organizational cultures, largely as a legacy of the country's past, it is still difficult to establish a homogenous culture of employee learning across different organizations. However, at national level, a framework can be established which can then be adapted at sectorial or organizational level to address the current problems.

Clearly an approach based entirely on the HCT will not deliver the best results given the need to address the deep social and structural problems impeding meaningful employee learning in the country. Formulating employee learning policies, programs and strategies premised only on the productivity and profit goals will not help as those who come from disadvantaged backgrounds will always be left behind. On the other hand, relying entirely on critical realism for direction on an employee learning trajectory to take may also not be useful in light of globalization and the competitive nature of the world today. This paper therefore suggests a middle-of-the road approach based on both HCT and CR. This implies taking into consideration the productive and profit imperatives in designing employee learning programs and policies but, at the same time, also taking into account the country's past as a result of which a significant section of the population still cannot be catered for by an approach that assumes that all people compete for jobs and work-related learning opportunities on the same footing. The country, as it has already done in some instances, can also borrow from different employee models in a bid to make its own programmes more inclusive, effective, sustainable and empowering. This implies, for example, putting in place legislation governing employee learning but also allowing employers some measure of autonomy in running employee learning programmes.

A question that arises from the suggestion to take a middle-of-the road approach relates to the specific features of the culture that can be built by taking a middle of the road approach. The first step in characterizing the envisaged culture should be based on what kind of society South Africa wants to be. If, for example, the intention, as is alluded to by most government and political leaders, is bring about socio-economic equity, then the culture of employee learning should have features intended to achieve that goal. One such feature is that the employees should be ready for work-related learning. This helps to avert a situation whereby the opportunities for work-related learning are there but the employees are not ready to take them or they take them but there is inefficiency in the way the opportunities are utilized because of weaknesses in the educational backgrounds of the employees. A starting point could perhaps be addressing the well-documented problems in basic education. This implies ensuring that all children irrespective of social class get more or less the same quality of education. This is necessary because once children receive more or less the same quality of education it enhances their chances of competing on an even 
footing for both post-school learning job opportunities. It also means that when they leave school to enter the job market, they are also at about the same level of readiness in terms engaging in work-related learning. Secondly, the culture of employee learning should be characterized by support by employers for employee learning and total commitment by the employees to engage in such learning. Other stakeholders such as the trade unions should also be solidly supportive of employee learning programs. So too should government through its various agencies. For example, there is a need to reconfigure the SETAs and redefine both their roles and approach as opposed to the current situation wherein they are being accused of ripping off employers by not only failing to channel back skills development levies to employers but also making the process of accessing the funds meant for employee learning, “... so hard to understand and so complicated to navigate that the majority of member companies give up." (Blumenthal, 2015: p. 2). Collaboration amongst all the parties will most likely contribute to the creation of a strong culture of employee learning as it will ensure that it is not only the concerns of one party that are foregrounded in the formulation of employee learning policies and programs. The culture of employee learning in South Africa should also be characterized by reflection on the part of all stakeholders at all levels. This will assist with rectification of weaknesses in the culture and enhancement of what will be working well. Lastly, benchmarking with international best practice, which however, takes account of the local context, would also go a long way in creating a culture if employee learning which enables the country to remain globally competitive economically while at the same time catering for its unique social conditions.

\section{References}

Almendarez, L. (2011). Human Capital Development: Implications for Educational Development at http://www.open.uwi.edu/sites/default/files/bnccde/belize/conference/papers2010/almendarez.html accessed 10 August 2015

Archer, M. (2006). Realist Social Theory: The Morphogenetic Approach, Cambridge, Cambridge University Press.

Baatjes, B. Skills, jobs and deception In Vally \& Motala (eds) (2014). Education, economy \& society, Pretoria, University of South Africa Press

Armstrong, M. (2007). A Handbook of Human Resource Management Practice, London, Kogan Page.

Bhaskar, R. (1998), "Facts and values: theory and practice", in Archer, M.S., Bhaskar, R., Collier, A., Lawson, T. and Norrie, A. (Eds), Critical Realism: Essential Readings, London, Routledge, pp. 409-43.

Blumenthal, I. (2015). ‘Are employers being ripped off?’ In The Star Workplace, 9 September (p.2).

Christian K. (2015). 'Competitiveness and Clusters: Implications for New European Growth Strategy, at www.foreorope.eu, accessed 23 September 2015.

Collier, A.; Lawson, T.E., Norrie, A. Centre For Critical Realism. London: Routledge.

Conner, M.L., \& Clawson, J.G. (2004). Creating a Learning Culture: Strategy, Technology and Practice, Cambridge, Cambridge University Press. http://dx.doi.org/10.1017/CBO9781139165303

Durkovic, J.V. (2009). 'Development of human resources as strategic factors of the company's competitive advantage.' Facta Universitatis, (Economics and Organization Series) 6 (1). Pp59-67.

Edutel Skills Development. (2010). Promoting a culture of employee learning in an organization, Johannesburg, Edutel.

George G., Surgey, G. \& Gow, J. (2014). 'South Africa's private sector investment in training and its erosion as a result of HIV and AIDS.' SAJEMS NS (2014) No. 2 pp 109-123.

Gillies, D. (2014). Human Capital, Education and Sustainability. Sisphus Journal of Education (2) 3 pp78-99.

Jarvis, P. (2007). Globalisation, Lifelong Learning and the Learning Society: Sociological Perspectives. Volume 2, Routledge Taylor \& Francis, London.

Jones, S. (1996). Developing a Learning Culture: Empowering people to deliver quality, innovation and long-term success, London, McGraw-Hill Company.

Kraak, A \& Hall, G. (1999). Transforming further education and training in South Africa, HSRC Publishers, Pretoria.

Livingstone, D. (1997). The limits of human capital theory: Expanding knowledge, informal learning and underemployment. Policy Options, July/ August, 9-13.

Lehola, P. (2011). 'Poverty Trends in South Africa- An examination of absolute poverty between 2006 and 2011' at 
www.statssa.gov.za accessed 21 September 2015.

Maluleke, T. (2014). 'Set course for a new destination: Higher education is no longer a luxury but a necessary resource for global competitiveness'. In the Mail \& Guardian, April 4 to 10 (pp36).

Marwala, T. (2015). 'Postgrad study key to development.' In the Mail \& Guardian, September 4 to 10 (p.35).

Morton, P. (2006). Using critical realism to explain strategic information systems planning. JITTA : Journal of Information Technology, Theory and Application, 8(1), 1.

Mnyandu, E. (2011). 'Without Skills, SA will lose its leading place in Africa' in The Star Business Report (June 13, pg14).

Msomi, S. (2011). 'Tell us about the SA you want-Manuel' in the Sunday Times June 12, pp4.

Mtshali, N. (2014). 'Parties fixated with same ideas on education- expert' in The Star, April 16 (pp8).

Msthali, N. (2014). 'African universities should solve African issues: Education institutions must focus on local areas of study' in The Star, September, 9 (pp9).

Mullins, L.J. (2006). Management and Organizational Behaviour, New York, Prentice Hall.

Mutch, A. (2004). 'Constraints on the Internal Conversation: Margaret Archer and the structural shaping of thought' in Journal for the Theory of Social Behaviour 34: 4 0021-8308 (pp 430-445).

Nzimande, B. (2013). National Skills Development 111 at www.gov.za, accessed 19 June 2015.

Olaniyan, D.A., \& Okemakinde, T. (2008). Human Capital Theory: Implications for Educational Development. European Journal of Scientific Research. Retrieved July 16, 2015 from http://www.eurojournals.com/ejsr_24_2_01.pdf

Ngcwangu, S \& Balwanz, D. (2014). 'The language of 'skills shortage' and the insufficiency of 'skills shortage' language: DHET and scarce skills.’ Post-School Education Review (1) 2 pp 15-17

Senge, P. (2006). The Fifth Discipline: The Art and Practice of the Learning Organization, New York, Currency Doubleday.

Schein, E.H. (2004). Organizational Culture and Leadership, San Francisco, Jessey-Bass.

Sibiya, A. (2014). 'South Africa has a jobs crisis and not skills shortages' in Sowetan, April, 15 (pp 11).

Swanepoel, B. (ed). (2001). South African Human Resource Management-Theory and Practice, Cape Town, Juta and Company Ltd.

Tshilongamulenzhe, M.C. \& Coetzee, M. (2013). Practising Training and Development in South African Organizations, Cape Town, Juta Press.

UNDP. (2014). 'Global Development Index for South Africa 2014'.

Valley, S. \& Motala, E. (eds). (2014). Education, Economy \& Society, Pretoria, UNISA Press.

Van Dyk, P.S., Nel, P.S., Van Loedolff, P.Z. \& Haasbroek, G.D. (1997). Training Management: A multidisciplinary approach to human resources development in Southern Africa, International Thompson Publishing (Southern Africa) (Pty) Ltd, Johannesburg.

Workplace Staff. (2014). 'Skills development is good for business' in The Star Workplave, April, 23 (page 12).

www.gov.za National Qualifications Act 67 of 2008 accessed 19 June 2015. 